Hegemonia - Revista Eletrônica de Relações Internacionais do Centro Universitário Unieuro

ISSN: 1809-1261

UNIEURO, Brasília, número 18, 2016, pp 297-310.

Recebido em: $12 / 8 / 2015$

Avaliado em:19/11/2015

Aprovado em: 15/12/2015

\title{
Tomando o Céu de Assalto: Apontamentos sobre o Refúgio no Brasil
}

Resumo: O artigo explora a evolução recente das políticas de refúgio no Brasil. O assunto é abordado sob uma perspectiva de proteção internacional dos direitos humanos. Nesse sentido, são objeto de análise as principais instituições, normativas e atores sociais com vínculos e interesses no assunto em questão.

Palavras-chave: Refúgio; Proteção Internacional dos Direitos Humanos; Ação Humanitária; Brasil.

Abstract: The article explores recent developments in policies of refugee in Brazil. The subject is approached under a perspective of international legal protection of human rights. In this sense, are subject to analysis the main institutions, legislation and social actors with links and interests on the issue at hand.

Key-words: Refugee; International protection of human rights; Humanitarian Action; Brazil.

Introdução

O propósito do presente texto é refletir sobre as políticas brasileiras de proteção dos refugiados, tendo como parâmetro de comparação a situação macro-regional, isto é, latino-americana. Nessa linha, particular interesse tem a reflexão sobre a evolução recente da proteção dos refugiados no Brasil, e

\footnotetext{
1 Doutor em História e docente do Unieuro.
} 
Artigo original

Hegemonia - Revista Eletrônica de Relações Internacionais do Centro Universitário Unieuro

ISSN: 1809-1261

UNIEURO, Brasília, número 18, 2016, pp 297-310.

sobre as convergências e divergências existentes na matéria entre o Brasil e seus vizinhos.

O assunto tem certamente relevância. De partida, cumpre constatar que - Brasil realmente forma parte do grupo de vanguarda no cenário latinoamericano de proteção dos refugiados e de afirmação da dignidade humana. Observe-se que o Brasil assinou e ratificou todos os principais instrumentos sobre proteção dos refugiados no continente e no mundo, com destaque para a Convenção das Nações Unidas Relativa ao Estatuto dos Refugiados (de 1951) e seu Protocolo Adicional (1967), bem como a Convenção Americana de Direitos Humanos (de 1969) e outros documentos semelhantes de âmbito latinoamericano. Paralelamente o Brasil apoia ativamente os trabalhos do Alto Comissariado das Nações Unidas para os Refugiados - ACNUR -, participa nos foros latino-americanos sobre o problema-objeto, e oferece proteção a oito mil quinhentos refugiados procedentes de quase oitenta países - erigindo-se em um dos mais importantes Estados latino-americanos em acolher refugiados, junto com o Equador e a Costa Rica.

A liderança brasileira na proteção dos refugiados também é evidente no campo da legislação específica - com destaque para a Lei 9474, de 1997 -, com a existência de instâncias deliberativas tripartites - eis o caso do Comitê Nacional para os Refugiados, CONARE -, e de iniciativas mais ousadas em matéria de soluções duráveis para esse desafio de natureza humanitária.

Cumpre acrescentar que os significativos e exemplares avanços brasileiros na temática da proteção dos refugiados parecem ter afinidades eletivas com as tendências mais gerais de sua inserção internacional macroregional, continental e global. Em outras palavras, a atualização de boas práticas em matéria de refúgio poderia formar parte de uma estratégia de política internacional construtiva nos primeiros anos do século XXI. Nesse caso, existiria uma complexa divisão de tarefas entre o Estado - especialmente no nível federal -, a sociedade civil, e certos atores não-estatais com vínculos e 
Artigo original

Hegemonia - Revista Eletrônica de Relações Internacionais do Centro Universitário Unieuro

ISSN: 1809-1261

UNIEURO, Brasília, número 18, 2016, pp 297-310.

interesses na temática - isto é, o ACNUR. Todos eles interessados em impulsionar uma melhor inserção brasileira no cenário internacional, em geral, e na questão da proteção dos refugiados, em particular.

Seja como for, também é evidente que assumir altas e crescentes responsabilidades na proteção dos refugiados exige formular e implementar políticas públicas e alocar escassos recursos humanos e materiais. Também é necessário terminar de convencer os atores políticos internos sobre a relevância da questão, e divulgar informação sobre o assunto para o grande público, que normalmente desconhece a realidade da maioria dos refugiados e suas eventuais contribuições ao processo de desenvolvimento humano dos diferentes países. A esse respeito parece pertinente comentar que algumas vezes os refugiados são enxergados pelo grande público como foragidos, concorrentes no mercado de trabalho, e eventualmente até como malfeitores. Obviamente é preciso mudar gradualmente essas apreciações. Essa mistura de cautela, curiosidade, preconceito e empáfia com relação aos refugiados somente poderá ser superada pelo esforço convergente e persistente entre o Estado e a sociedade civil - principalmente das instituições religiosas e de certas organizações não-governamentais presentes tanto no Brasil quanto em outros países.

Luzes e sombras na construção da liderança regional do Brasil na proteção dos refugiados

Nos primeiros anos do século XXI, o Brasil logrou assumir funções de maior protagonismo na proteção internacional dos refugiados. A liderança brasileira nessa matéria está ligada aos consistentes alicerces político-jurídicos que amparam a prestação de serviços públicos de alta qualidade, bem como das facilidades colocadas à disposição dos refugiados. Em outras palavras, é na qualidade do refúgio - e não necessariamente na quantidade de refugiados 
Artigo original

Hegemonia - Revista Eletrônica de Relações Internacionais do Centro Universitário Unieuro

ISSN: 1809-1261

UNIEURO, Brasília, número 18, 2016, pp 297-310.

acolhidos - que o povo e o governo brasileiros demonstram sua vontade de trabalhar na temática. Certamente outros países latino-americanos, como Equador e a Costa Rica, reportam quantidades superiores de refugiados especialmente de origem colombiana - albergados em seus respectivos territórios. Nessa linha, parece pertinente comentar que, no inicio de 2015, o governo brasileiro reconhecia o status de refugiado a mais de quatro mil setecentas pessoas.

Para os fins desse artigo é particularmente relevante examinar três tópicos diretamente relacionados ao problema-objeto: (i) a legislação brasileira sobre a proteção dos refugiados, (ii) o desempenho do CONARE, e (iii) algumas políticas inovadoras em matéria de solução durável para os refugiados.

\section{A Lei 9474}

Existe um virtual consenso entre autoridades, pesquisadores, beneficiários e outras pessoas com vínculos e interesses na temática da proteção dos refugiados sobre as bondades e o vanguardismo da lei brasileira. Em nível macro-regional ou latino-americano, a legislação brasileira é destaque ao reconhecer e assumir os principais avanços nesse campo, com virtuosos desdobramentos institucionais e societais.

Resumidamente, a mencionada Lei coloca no seu primeiro artigo uma definição de refugiado que combina de forma consistente os clássicos "fundados temores de perseguição" em virtude de raça, religião, nacionalidade, filiação em certo grupo social ou das opiniões políticas, de um lado, com a questão dos apátridas e da preocupação latino-americana pela "grave e generalizada violação dos direitos humanos", de outro. Ao complementar e harmonizar o legado mundial e o denominado espírito da Declaração de 
Artigo original

Hegemonia - Revista Eletrônica de Relações Internacionais do Centro Universitário Unieuro

ISSN: 1809-1261

UNIEURO, Brasília, número 18, 2016, pp 297-310.

Cartagena de 1984 e documentos subsequentes (especialmente o Plano de Ação do México, de 2004, e a Declaração de Brasília, de 2010), a legislação brasileira logrou um avanço paradigmático e se colocou eficientemente no grupo vanguardista das legislações sobre proteção aos refugiados existentes no continente latino-americano.

Nos artigos subsequentes da Lei 9474/97 instrui-se sobre a organização de uma instância colegiada de deliberação e de elegibilidade - isto é, o CONARE - , oferece aos refugiados procedimentos mais transparentes, expeditos e humanitários para realizar os requerimentos burocráticos, e inova no processo de tomada de decisões. A mencionada lei também reconhece as denominadas soluções duráveis propostas pelo ACNUR para os refugiados, quais sejam: a repatriação, a integração local, e/ou o reassentamento. Outrossim, parece existir dentro da mencionada norma um equilíbrio virtuoso e dinâmico entre as legítimas aspirações de proteção dos refugiados, de um lado, com as igualmente legítimas e necessárias preocupações de segurança do Estado e da sociedade brasileiras.

Em suma, conclui-se que a Lei brasileira sobre proteção dos refugiados está alicerçada nos entendimentos mais modernos sobre o assunto. É bem provável que seus desdobramentos também possam ser verificados nas leis homólogas de países vizinhos - particularmente do Cone Sul e em países andinos - aprovadas nos primeiros anos do século XXI.

O Comitê Nacional para os Refugiados - CONARE

A criação do CONARE, em 1998, é um resultado da Lei 9474/97. Resumidamente trata-se de instancia de elegibilidade colegiada e integrada de forma tripartite - isto é, composta por membros do governo federal (com direito a voz e voto), por membros da sociedade civil organizada (com direito a voz e voto) e pelo ACNUR (com direito a voz, porém sem direito ao voto). 0 
Artigo original

Hegemonia - Revista Eletrônica de Relações Internacionais do Centro Universitário Unieuro

ISSN: 1809-1261

UNIEURO, Brasília, número 18, 2016, pp 297-310.

CONARE instituiu-se como uma primeira instância técnico-burocrática dedicada à regulação das questões ligadas à proteção dos refugiados no Brasil. Normalmente corresponde ao CONARE avaliar os pedidos de reconhecimento do status de refugiado, ponderar sobre a cessão e/ou perda do status, coordenar os serviços interinstitucionais oferecidos pelo Estado brasileiro aos refugiados, dentre outros. Cumpre acrescentar que cabe ao Ministro da Justiça convalidar (ou não), em segunda instância, as determinações do CONARE caso haja recurso das decisões.

Entre 1998 e 2016, o CONARE tomou conhecimento de mais de 10 mil solicitações de refúgio. Reconheceu o status de refugiado em mais de oito mil casos, e indeferiu outros - normalmente por falta de credibilidade do requerente. Cumpre acrescentar que os refugiados no Brasil são procedentes de quase oitenta países, além de alguns apátridas. Os principais contingentes de refugiados no Brasil são procedentes da África (principalmente naturais de Angola, Congo e Libéria), de Oriente Médio (principalmente da Síria e Palestina) e das Américas (principalmente colombianos).

Observe-se que esses refugiados moram livremente nas cidades brasileiros, eles têm os mesmos direitos dos outros estrangeiros residentes e estão submetidos às mesmas vicissitudes que o resto da população brasileira. Em consequência, não existem campos de refugiados administrados pela ACNUR em território brasileiro. A maioria dos refugiados vive nos Estados do Rio de Janeiro, São Paulo, Rio Grande do Sul, Paraná e no Distrito Federal. Eles interagem com a população local. Em geral, o cotidiano desses refugiados é semelhante ao da maioria da população brasileira, particularmente no que diz respeito ao acesso aos serviços sociais básicos, ao mercado de trabalho, e a outras dimensões da vida em sociedade. Sendo que, em não poucos casos, os refugiados no Brasil padecem de dificuldades específicas com relação ao processo de integração local. Eis os casos do domínio da língua portuguesa, das convergências e divergências culturais, dos problemas de identificação e 
Artigo original

Hegemonia - Revista Eletrônica de Relações Internacionais do Centro Universitário Unieuro

ISSN: 1809-1261

UNIEURO, Brasília, número 18, 2016, pp 297-310.

documentação oficial, de saudades com relação ao país de origem, e de incertezas sobre o devir das próprias vidas e de seus descendentes.

Nesse contexto, o CONARE coordena as atividades e serviços públicos colocados à disposição dos refugiados pelo governo e pela sociedade brasileira. No cumprimento dessas tarefas o CONARE tem 0 apoio de atores governamentais (Ministérios das Relações Exteriores, Trabalho e Emprego, Saúde, Educação, Polícia Federal, e entidades subnacionais). Também existe apoio de atores não estatais, como algumas instituições religiosas (como as Caritas Arquidiocesanas de São Paulo, Manaus e do Rio de Janeiro, a Associação Antônio Vieira, o Instituto de Migrações e Direitos Humanos, e o Centro de Defesa dos Direitos Humanos), organismos internacionais (ACNUR), entidades de classe, e do mundo social, político, econômico e acadêmico. Todos esses atores procuram trabalhar de forma coordenada, e oferecem apoio financeiro, serviços públicos, apoio psicológico, treinamento profissional, dentre outros.

Sob uma perspectiva latino-americana parece evidente que o CONARE do Brasil atende favoravelmente muitas das avaliações e parâmetros internacionais. Os intercâmbios de experiências entre o CONARE brasileiro e seus homólogos de países vizinhos são constantes. Certamente todas essas instituições podem melhorar seus processos de tomada de decisões e a implementação de políticas de proteção dos refugiados - sem esquecer as limitações orçamentárias e de outros recursos humanos e materiais que estão presentes nas diferentes unidades administrativas. Mesmo assim, cumpre destacar que são relativamente poucas as reclamações de refugiados sobre o trabalho do CONARE e outros atores com vínculos e interesses na temática. Igualmente, os princípios da não-devolução e do In dúbio pro refugiado são escrupulosamente respeitados - sendo isto válido inclusive quando o requerimento de reconhecimento do status de refugiado acaba sendo indeferido pelas autoridades competentes. Em consequência é evidente a 
Artigo original

Hegemonia - Revista Eletrônica de Relações Internacionais do Centro Universitário Unieuro

ISSN: 1809-1261

UNIEURO, Brasília, número 18, 2016, pp 297-310.

preocupação e o profissionalismo na tentativa de evitar a exclusão de legítimos solicitantes desse status humanitário no contexto geral de altos e crescentes fluxos migratórios mistos.

Assim, e salvo melhor interpretação, podemos concluir que as boas práticas do CONARE dão continuidade à essencialmente virtuosa trajetória do instituto do refúgio e do asilo na América Latina. Ou, em outras palavras, o CONARE também contribui ativamente no excelente desempenho brasileiro na proteção dos refugiados e na liderança do país nessa temática a nível macroregional, continental e global.

O reassentamento no Brasil: notícias sobre uma inovadora solução durável para os refugiados

Segundo o ACNUR e a legislação brasileira existem três tipos principais de soluções duráveis aos desafios colocados pela proteção dos refugiados, quais sejam: o reassentamento, a repatriação e a integração local. Das soluções duráveis mencionadas a mais recente e interessante para os fins deste estudo é o reassentamento. Resumidamente o reassentamento supõe que, prévio acordo entre o ACNUR e um governo disposto a acolher refugiados, pessoas com o mencionado status já reconhecido por um Estado são - voluntariamente - transferidos para um terceiro país. O reassentamento normalmente acontece quando refugiados não podem retornar para o país de origem e continuam se sentindo ameaçados no primeiro país que concedeu o status. Eis os casos de colombianos ou afegãos que, após serem reconhecidos como refugiados pelos governos do Equador e de certos países do Oriente Médio, respectivamente, e de um prévio acordo entre o Brasil e o ACNUR, acabaram sendo acolhidos em território brasileiro.

Observe-se que são poucos os casos de reassentamentos realizados pelo ACNUR em países latino-americanos, particularmente quando se trata de 
Artigo original

Hegemonia - Revista Eletrônica de Relações Internacionais do Centro Universitário Unieuro

ISSN: 1809-1261

UNIEURO, Brasília, número 18, 2016, pp 297-310.

refugiados oriundos de outros continentes. Segundo dados do ACNUR, o Brasil e o Chile são os países latino-americanos mais ativos no que diz respeito à implementação de iniciativas de reassentamento. $O$ Brasil oferece reassentamentos desde 2002, quando um primeiro grupo de afegãos foi acolhido no Estado do Rio Grande do Sul. No momento de escrever esse texto, aproximadamente 460 refugiados no Brasil foram objeto de reassentamento em coordenação com ACNUR. A maioria dos refugiados reassentados é de origem colombiana, síria e palestina.

Os resultados obtidos com os reassentamentos solidários são positivos, porém não estão livres de certas vicissitudes e de não poucos ensinamentos que deverão aperfeiçoar essa proposta de solução durável no futuro. Tal foi o caso de certo agrupamento de refugiados de origem palestina que foram reassentados e que, em determinado momento, passaram a reivindicar do governo brasileiro facilidades para viajar para a França e outros países europeus, onde aparentemente pretendiam residir com seus familiares. Em consequência, o apoio institucional, do ACNUR e da sociedade civil organizada continuará sendo vital para a manutenção e o aperfeiçoamento dos reassentamentos de refugiados em território brasileiro.

Nessa linha, parece evidente que o pioneirismo do Brasil na implementação de iniciativas de reassentamento demonstra de forma bastante evidente o interesse e a disposição do país em assumir os riscos, os custos, as oportunidades, a liderança e o compromisso na proteção dos refugiados no contexto regional e global.

Considerações finais

Desde 2016, o principal contingente de refugiados no Brasil passou a ser integrado por sírios. O conflito armado naquele país, acabou modificando a composição do conjunto dos refugiados presentes no Brasil, já que durante 
Artigo original

Hegemonia - Revista Eletrônica de Relações Internacionais do Centro Universitário Unieuro

ISSN: 1809-1261

UNIEURO, Brasília, número 18, 2016, pp 297-310.

muito tempo foram refugiados procedentes de Angola e da Colômbia nos predominantes no país. Recentemente, muitos angolanos deixaram esse status de proteção em virtude da cessação no país de origem das circunstâncias que motivaram o reconhecimento - isto é, a perseguição política no marco do conflito armado interno. Os refugiados angolanos seguramente passarão a gozar de um visto permanente, alguns retornaram para seu país de origem (isto é, a repatriação voluntária) e outros provavelmente optarão pela naturalização e pela cidadania brasileira (isto é, a inclusão local definitiva). Paralelamente, o segundo contingente de refugiados no Brasil, integrado pelos colombianos, certamente está acompanhando as negociações de paz entre Bogotá e as guerrilhas. Caso o conflito colombiano seja resolvido pela via negociada provavelmente esse contingente de refugiados terminará procurando alternativas semelhantes às dos homólogos angolanos - quer dizer, a repatriação ou a integração. Esses cenários prospectivos e suas implicações quantitativas e qualitativas podem resultar em importantes mudanças e continuidades para a liderança brasileira na proteção dos refugiados. Observese que, até recentemente, os refugiados angolanos e colombianos juntos representam a metade de todos os refugiados reconhecidos pelo governo brasileiro. Certamente essa situação mudou-se radicalmente desde o acirramento do conflito sírio.

Afortunadamente, o Brasil e a América Latina parecem encaminhadas a erigir-se em zonas de paz, de cooperação e também de acolhimento de refugiados procedentes de outros continentes, situação semelhante ao que atualmente acontece na Europa ocidental, na América do Norte (Estados Unidos e Canadá), e na Austrália. Tudo isso fala muito bem do desempenho brasileiro e latino-americano em matéria de proteção dos refugiados e do asilo. Com efeito, é evidente que o Brasil possui uma consistente política sobre o refúgio, apoiada por atores, mecanismos e procedimentos internos, por recursos financeiros consideráveis, e pelo reconhecimento internacional - seja 
Artigo original

Hegemonia - Revista Eletrônica de Relações Internacionais do Centro Universitário Unieuro

ISSN: 1809-1261

UNIEURO, Brasília, número 18, 2016, pp 297-310.

regional, continental ou global.

Seja como for, é igualmente evidente que ainda existem desafios pendentes para aprimorar os mecanismos e as facilidades colocadas à disposição dos refugiados. Particularmente urgente é a questão dos documentos de identificação fornecidos pelo Estado aos refugiados, bem como fortalecer as capacidades técnicas do CONARE. Também é relevante a divulgação da problemática e dos desafios da proteção dos refugiados na imprensa e no grande público. Aprofundar o trabalho e o intercâmbio de experiências entre as agências especializadas na proteção dos refugiados dos diferentes países latino-americanos redundará em melhores serviços. Nessa linha, o paradigmático trabalho do CONARE brasileiro pode ser divulgado entre os homólogos de outros países do continente, principalmente na região dos Andes e da bacia do Caribe.

Em conclusão, entende-se que o futuro da liderança regional do Brasil na proteção dos refugiados passará pelo esforço na atenção e na prestação de melhores serviços aos refugiados, na divulgação das boas práticas sobre refugiados nos países vizinhos, implementando novas e melhores iniciativas de reassentamento, acompanhando as pesquisas de ponta no problema-objeto, e eventualmente tentando assumir cargos e responsabilidades mais elevadas nas instituições especializadas - com destaque para o ACNUR.

Fontes e Referências

Documentos oficiais

Brasil, "Lei n. 9474, de 22 de julho de 1997." Disponível em: http://www.planalto.gov.br/ccivil_03/Leis/L9474.htm. Consulta em 17.5.2013. 
Artigo original

Hegemonia - Revista Eletrônica de Relações Internacionais do Centro Universitário Unieuro

ISSN: 1809-1261

UNIEURO, Brasília, número 18, 2016, pp 297-310.

Organização das Nações Unidas, "Convenção de Genebra Relativa ao Estatuto dos Refugiados de 1951." Disponível em: www.unric.org. Consulta em 17.5.2013.

\section{Literatura}

Barbosa, Luciano, e Sagrado da Hora, José, A Polícia Federal e a proteção internacional dos refugiados. Brasília: Acnur, 2007.

Barreto, Luiz Paulo (org.), Refúgio no Brasil. A proteção brasileira aos refugiados e seu impacto nas Américas, Brasília: Acnur e Governo Federal, 2010.

Cançado Trindade, Antônio, e Ruiz de Santiago, Jaime (orgs.), La nueva dimensión de las necesidades de protección del ser humano en el inicio del siglo XXI. San José: CIDH e Acnur, 2003.

Domínguez, Juliana, e Baeninguer, Rosana, "Programa de Reassentamento de Refugiados no Brasil". Disponível em www.migrante.org.br. Consultado em 15.5.2015.

Franco, Leonardo (org.), El Asilo y la Protección Internacional de los Refugiados en América Latina. Buenos Aires: Acnur, 2003.

Guild, Elspeth, Security and Migration in the $21^{\text {st }}$ Century. Cambridge: Polity Press, 2009.

Jubilut, Liliana, O Direito Internacional dos Refugiados e sua Aplicação no Ordenamento Jurídico Brasileiro. São Paulo: Método, 2007.

Leão, Renato, "O $15^{\circ}$ aniversário da Lei 9.474/97: a contribuição de Brasília para a consolidação do instituto do refúgio no Brasil", in Lidia Xavier, Carlos Domínguez Avila e Vicente Fonseca (orgs.), Direitos Humanos, Cidadania e Violência no Brasil: Estudos interdisciplinares. Curitiba: Editora CRV, 2013.

O reconhecimento dos refugiados pelo Brasil. Comentários sobre decisões do CONARE. Brasília: Acnur e Governo Federal, 2007. 
Artigo original

Hegemonia - Revista Eletrônica de Relações Internacionais do Centro Universitário Unieuro

ISSN: 1809-1261

UNIEURO, Brasília, número 18, 2016, pp 297-310.

Moreira, Júlia, "Redemocratização e direitos humanos: a política para refugiados no Brasil", Revista Brasileira de Política Internacional, 53 (1): 111129, 2010.

, "A problemática dos refugiados na América Latina e no Brasil", Cadernos Prolam/USP, 4 (2): 57-76, 2005.

Murillo, Juan Carlos, "Os legítimos interesses de segurança dos Estados e a proteção internacional de refugiados", Sur. Revista Internacional de Direitos Humanos, 6 (10): 120-137, 2009.

Ramos, André e outros (orgs.), 60 anos de Acnur. Perspectivas de futuro. São Paulo: Acnur, 2011.

Rocha, Rossana e Moreira, Júlia, "Regime Internacional para Refugiados: Mudanças e Desafios", Revista de Sociologia e Política, 18 (37): 17-30, 2010. 